\title{
Two-Stage Fault Diagnosis Method Based on the Extension Theory for PV Power Systems
}

\author{
Meng-Hui Wang and Mu-Jia Chen \\ Department of Electrical Engineering, National Chin-Yi University of Technology, Taichung 41110, Taiwan \\ Correspondence should be addressed to Meng-Hui Wang, wangmh@ncut.edu.tw
}

Received 28 March 2012; Accepted 19 April 2012

Academic Editor: Vincenzo Augugliaro

Copyright ( $) 2012$ M.-H. Wang and M.-J. Chen. This is an open access article distributed under the Creative Commons Attribution License, which permits unrestricted use, distribution, and reproduction in any medium, provided the original work is properly cited.

\begin{abstract}
In order to shorten the maintenance time and make sure of the photovoltaic (PV) power generation system steadily in operation, a fault diagnosis system for photovoltaic power generation system was proposed in this paper. First, a PSIM software is used to simulate a $2.2 \mathrm{~kW}$ PV system, it can take the operating date of the PV system under different sunlight intensity and temperature conditions. In this paper, a two-stage diagnosis system based on the extension theory for PV power systems is proposed; the proposed method is not only be able to troubleshoot the system fault but also the damaged module can also be located. The primary strategy is to utilize the diagnosis array of daylight identification and to use light scanning of the damage array at night. Via wireless network the data is transmitted back to the diagnosis system for identifying the location of damaged module. The time and energy of manually locating the fault module can be greatly saved. Finally, the methods as proposed in this paper have been compared with other existing methods, by which to verify its superiority and usability.
\end{abstract}

\section{Introduction}

Energy is the foundation of human development; since the industrial revolution, rapid industrial development around the world makes modern technology progress and improves life quality of people but results in dependence on oil increasing. After four oil crises, the global economy has made a considerable impact, leading to higher oil prices. Gradually while facing the shortage of fossil energy, coupled with excessive use of fossil fuels produces carbon dioxide increased year by year. It has caused upheaval and global climate warming, prompting the awakening of environmental protection and energy crisis consciousness. Therefore, restriction and mitigation of carbon dioxide produced by fossil fuels have become a part of the international community concern to pay attention to and have more positive impact on development and application of renewable energy, looking forward to finding the inexhaustible source of alternative energy $[1,2]$.

With the development of photovoltaic power generation technology having been good power supply system. In the great effort of governments to make solar power systems of increasing scale. A solar power system is usually composed of many solar cells in series or parallel composition of modules, and arrays are constituted by multiple modules to provide sufficient voltage and current, but the system is the greater the number of solar modules is more. In order to get enough sunshine to supply the load for solar power generation systems, all solar power generation systems are installed outdoors with no shelter and no shadow region, because the system is long-term setting for outdoors; there is dust covered making the photovoltaic modules generate masking module failure or damage occurrence, and efficiency of power generation system will significantly reduce; in addition, with the system operating for a long time, it easily makes photovoltaic modules aged and reduces output. Therefore, solar power system fault analysis is one of the important researches today. On the other hand, the wireless communication technology continues to develop. In recent years, the technicality of low cost wireless networking equipment emerges; it is called ZigBee [3]. It has low complexity, low power consumption, low price, is easy to implement; has a variety of network infrastructures, and so forth. It is able to reduce the manpower and time to repair, 


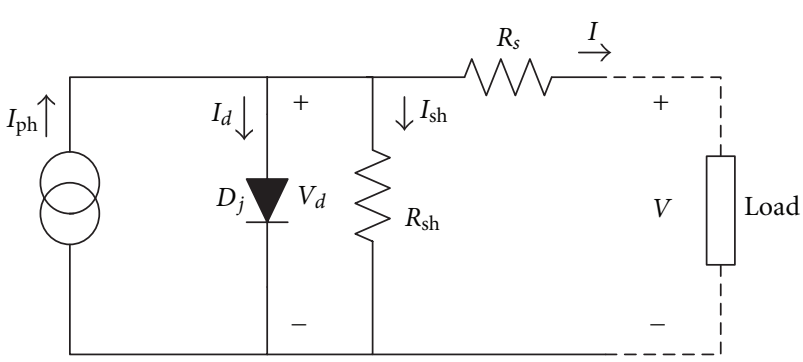

FIgure 1: Proton exchange membrane fuel cell power generation diagram.

to ensure the stable operation of the system, improving the remote management efficiency and reducing fault, and identify the fault type accurately.

This paper combines wireless sensor technology and extension fault diagnosis method, developing a useful solar fault diagnosis system. Cai [4] originally created the concept of extension theory to solve contradictions and incompatibility problems in 1983. In this world, there are some problems that cannot be directly solved by given conditions, but the problem may become easier or solvable through some proper transformation. For example, the Laplace transformation is one of the commonly used techniques in engineering fields, and the concept of fuzzy sets is a generalization of wellknown standard sets to extend application fields. Therefore, the concept of an extension set is to extend the fuzzy logic value from $[0,1]$ to $(-\infty, \infty)$, which allows us to define any data in the domain and has given promising results in many fields [5]. To demonstrate the effectiveness of the proposed method, a $2.2 \mathrm{~kW} \mathrm{PV}$ power system was tested. Results of the studied cases show that the proposed method is suitable as a practical solution.

\section{Math Model of PV Power Systems}

Solar cell is a P-N junction semiconductor; it converses light energy into electrical energy. The solar equivalent circuit is shown in Figure 1. $I_{\mathrm{ph}}$ represents current that the solar cell generated by light, $D_{j}$ represents the diode of P-N junction, and $R_{\mathrm{sh}}$ and $R_{s}$ are the series and parallel resistance of internal battery, respectively. The $I-V$ equation developed of solar cells is as follows:

$$
I=I_{\mathrm{ph}}-I_{\mathrm{sat}}\left[\exp \left(\frac{q\left(V+I R_{s}\right)}{A K T}\right)-1\right]-\frac{(V+I R)}{R_{\mathrm{sh}}} .
$$

In (1), $I_{\mathrm{ph}}$ is the light current source of solar cells under sunlight and temperature, $I_{\text {sat }}$ is the reverse saturation current of solar cells, $A$ is the ideal parameter of solar cells $(A=1 \sim 5), K$ is Boltzmann constant $\left(1.3806 \times 10^{-23} \mathrm{~J} /{ }^{\circ} \mathrm{K}\right)$, $q$ is electronic charge $\left(1.6 \times 10^{-19} \mathrm{C}\right)$, and $T$ is reference temperature of solar cells [6].

Because the characteristic of solar cells is changed by sunlight intensity and ambient temperature, so the P-V curves of PV systems are also unlike shapes under different operation conditions. Figure 2 shows the $I-V$ characteristic curve of the solar cell in fixed sunlight and different

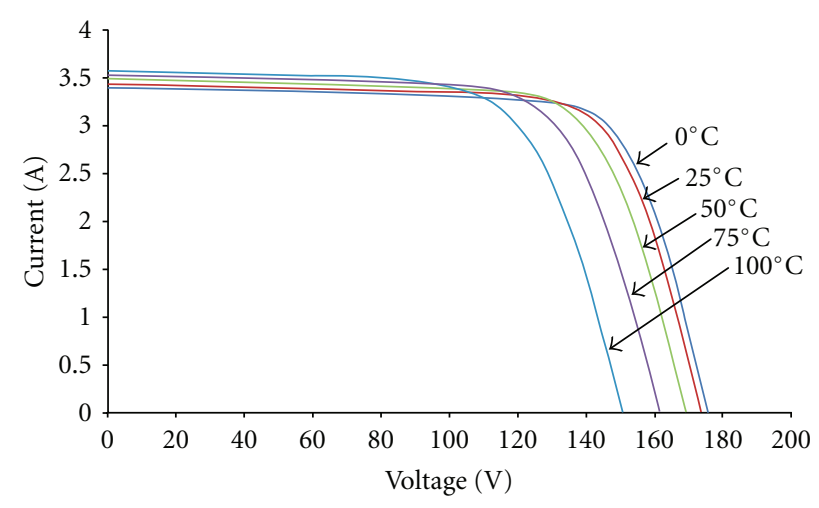

FIgURE 2: The $I-V$ characteristic curve of solar cells under different temperature.

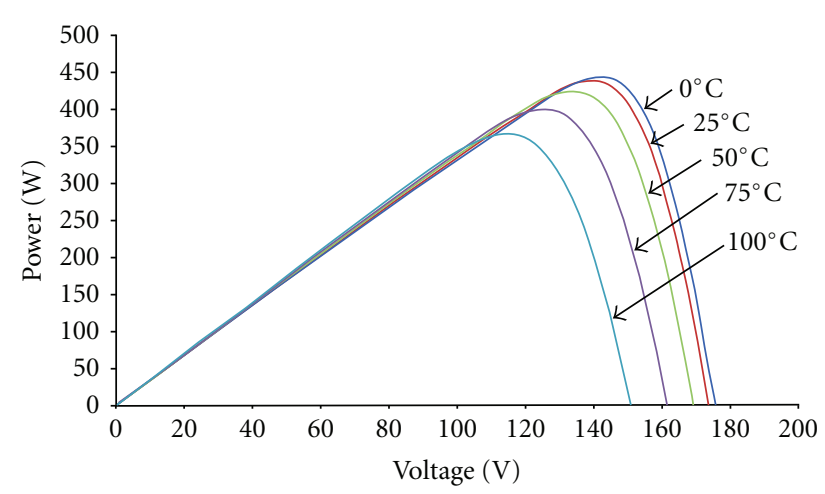

Figure 3: The $P-V$ characteristic curve of solar cells under different temperature.

temperature. Figure 3 shows the $P-V$ characteristic curve of the same condition. From the characteristic curve we can know when ambient temperature rises; the short-circuit current of solar cells changes slightly, but the open-circuit voltage of solar cells drops significantly. It leads the output power to be low, so we can know when we use solar cells and when we should avoid at high temperature.

In addition, according to different sunlight intensity, it would affect the characteristic curves of solar cells. Figures 4 and 5 are $I-V$ and $P-V$ characteristic curves of solar cells at fixed temperature but different sunlight intensity. From the curve, we can know if sunlight intensity increases and if the output power will increase, and vice versa.

\section{Review of Extension Theory}

In the standard set, an element either belongs to or does not belong to a set, so the range of the standard set is $\{0,1\}$, which can be used to solve a two-valued problem. In contrast to the standard set, the fuzzy set allows for the description of concepts in which the boundary is not explicit. It concerns not only whether an element belongs to the set but also to what degree it belongs to. The range of a fuzzy set is $[0,1]$. The extension set extends the fuzzy set from $[0,1]$ to $(-\infty, \infty)$. As a result, it allows us to define a set that 


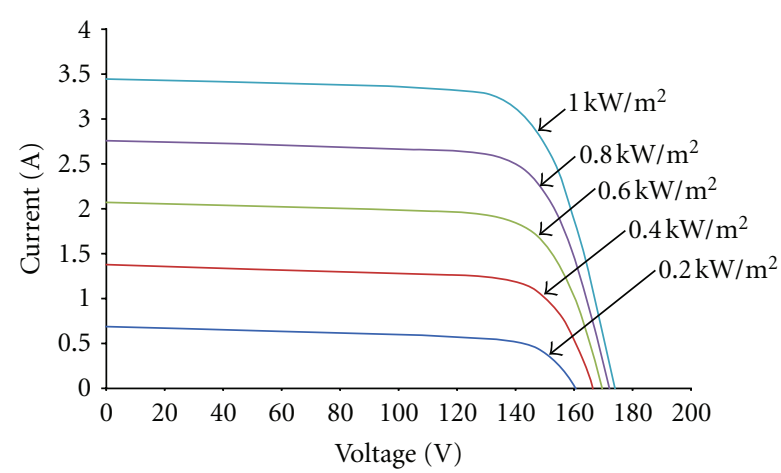

FIGURE 4: The $I-V$ characteristic curve of solar cells under different sunlight intensity.

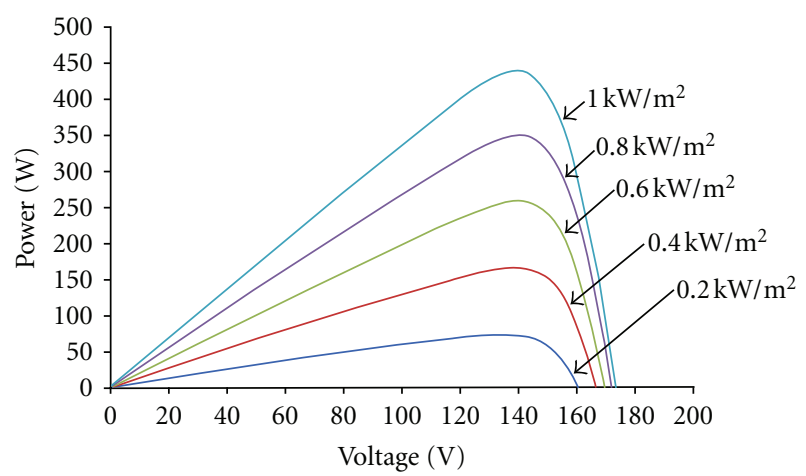

Figure 5: The $P-V$ characteristic curve of solar cells under different sunlight intensity.

includes any data in the domain. Extension theory tries to solve the incompatibility or contradiction problems by the transformation of the matter element. The comparisons of the standard sets, fuzzy sets, and extension sets are shown in Table 1. Some definitions of extension theory are introduced in the next section [7].

\subsection{Matter-Element Theory}

3.1.1. Definition of Matter Element. Defining the name of a matter by $N$, one of the characteristics of the matter by $c$, and the value of $c$ by $v$, a matter element in extension theory can be described as follows:

$$
R=(N, c, v),
$$

where $N, c$, and $v$ are called the three fundamental elements of the matter element. For example, $R=$ (John, Weight, $80 \mathrm{~kg}$ ) can be used to state that John's weight is $80 \mathrm{~kg}$.

3.1.2. Multidimensional Matter Element. Assuming $R=$ $(N, C, V)$ is a multidimensional matter-element, $C=$ $\left[c_{1}, c_{2}, \ldots, c_{n}\right]$ a characteristic vector, and $V=\left[v_{1}, v_{2}, \ldots, v_{n}\right]$ a value vector of $C$, then a multidimensional matter element is defined as

$$
R=\left[\begin{array}{c}
N, c_{1}, v_{1} \\
\mathrm{c}_{2}, v_{2} \\
\ldots \\
c_{n}, v_{n}
\end{array}\right]=\left[\begin{array}{c}
R_{1} \\
R_{2} \\
\ldots \\
R_{n}
\end{array}\right],
$$

where $R_{i}=\left(N, c_{i}, v_{i}\right)(i=1,2 \ldots n)$ is defined as the submatter-element of $R$, which can be simplified as follows:

$$
R=(N, C, V) \text {. }
$$

3.1.3. Divergence of Matter Element. A matter may have many characteristics; the same characteristics and values may also belong to some other matter. In extension theory, there are some formulations to express as follows.

Theory 1. If a matter has many characteristics, which can be written as

$$
N \dashv(N, c, v) \dashv\left\{\left(N, c_{1}, v_{1}\right),\left(N, c_{2}, v_{2}\right), \ldots,\left(N, c_{n}, v_{n}\right)\right\} .
$$

The symbol " $\dashv$ ” indicates the mean of the extension.

Theory 2. If some matter has the same characteristic, which can be written as

$$
(N, c, v) \dashv\left\{\left(N_{1}, c, v_{1}\right),\left(N_{2}, c, v_{2}\right), \ldots,\left(N_{n}, c, v_{n}\right)\right\} .
$$

Theory 3. If some matter has the same value, which can be written as

$$
(N, c, v) \dashv\left\{\left(N_{1}, c_{1}, v\right),\left(N_{2}, c_{2}, v\right), \ldots,\left(N_{n}, c_{n}, v\right)\right\} .
$$

\subsection{Summary of Extension Set Theory}

3.2.1. Definition of Extension Set. Let $U$ be a space of objects and let $x$ be a generic element of $U$; then an extension set $A$ in $U$ is defined as a set of ordered pairs as follows:

$$
A=\{(u, y) \mid u \in U, y=K(x) \in(-\infty, \infty)\},
$$

where $y=K(x)$ is called the relational function for extension set $A$. The $K(x)$ maps each element of $U$ to a membership grade between $-\infty$ and $\infty$. The higher the degree, the closer the element belongs to the set. Under a special condition, when $0 \leq K(x) \leq 1$, it corresponds to a normal fuzzy set. $K(x) \leq-1$ implies that the element $x$ has no chance to belong to the set. When $-1<K(x)<0$, it is called an extension domain, which means that the element $x$ still has a chance to become part of the set.

3.2.2. Definition of Distance. Let $x$ be a generic point of space $(-\infty, \infty)$ and let $X_{o}=\langle a, b\rangle$ be a concerned domain which is called a classical domain. Then the left-right-side distance from $x$ to $X_{o}$ is calculated as follows:

$$
\rho\left(x, X_{o}\right)=\left|x-\frac{a+b}{2}\right|-\frac{b-a}{2} .
$$


TABLE 1: Three different sorts of mathematical sets.

Compared item

Research objects

Model

Descriptive function

Descriptive property

Range of set
Standard set

Data variables

Mathematics model

Transfer function

Precision

$C_{A}(x) \in(0,1)$
Fuzzy set

Linguistic variables

Fuzzy mathematics model

Membership function

Ambiguity

$\mu_{A}(x) \in[0,1]$
Extension set

Contradictory problems

Matter-element model

Correlation function

Extension

$K_{A}(x) \in(-\infty, \infty)$

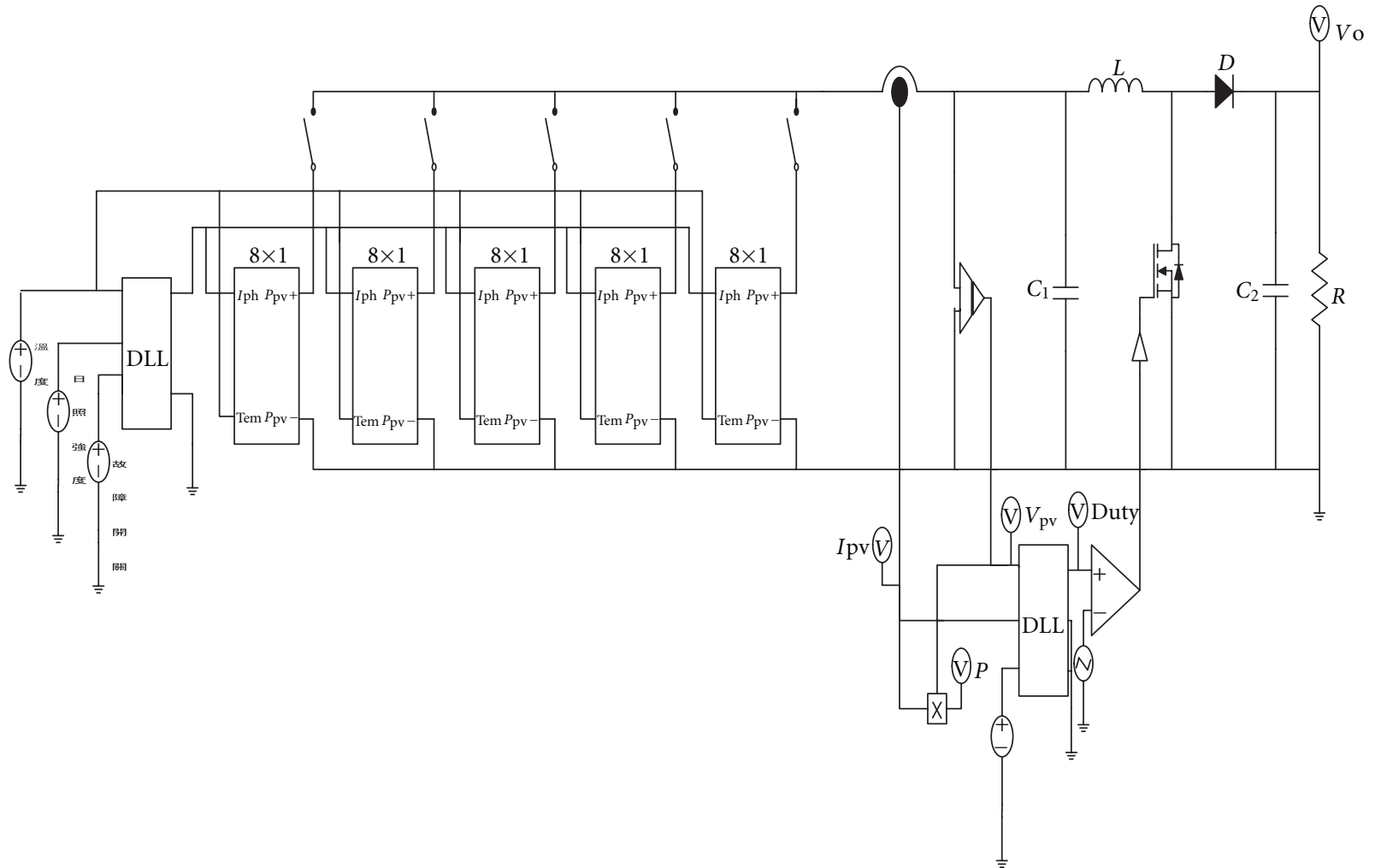

FIGURE 6: The solar power system by PSIM simulation software.

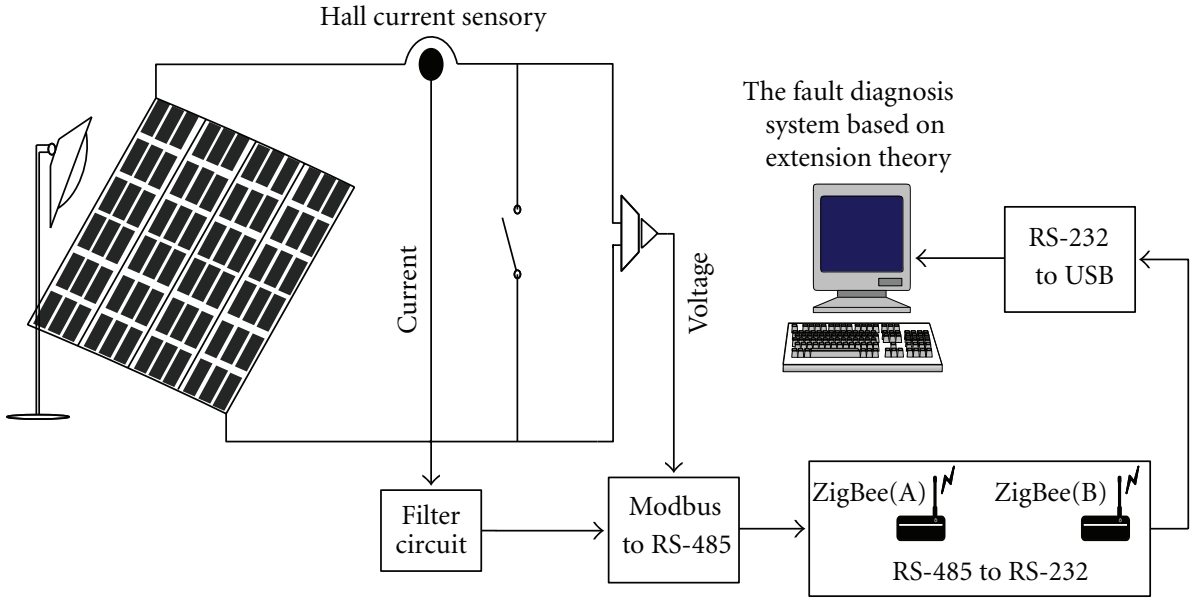

Figure 7: The architecture of diagnosis system for remote photovoltaic power generation. 
3.2.3. Distance Values. Let $X_{o}=\langle a, b\rangle$, let $X=\langle c, d\rangle$, and let $X_{o} \in X$, where $X_{o}$ and $X$ are the classical and neighborhood domains, respectively. Then the left-right-side distance value from $x$ to $X_{o}$ and $X$ is calculated as follows:

$$
D\left(x, X_{o}, X\right)= \begin{cases}\rho(x, X)-\rho\left(x, X_{o}\right) & x \notin X_{\mathrm{o}} \\ -1 & x \in X_{\mathrm{o}} .\end{cases}
$$

3.2.4. Primitively Extended Relation Function. Let $X_{o}=$ $\langle a, b\rangle$, let $X=\langle c, d\rangle$, and let $X_{o} \in X$; the extended relation function can be defined as follows:

$$
K(x)=\frac{\rho\left(x, X_{o}\right)}{D\left(x, X_{o}, X\right)} .
$$

The relation function can be used to calculate the membership grade between $x$ and $X_{o}$. The extended membership function is shown in Figure 1 . When $K(x) \geq 0$, it indicates the degrees to which $x$ belongs to $X_{o}$. When $K(x)<0$, it describes the degree to which $x$ does not belong to $X_{o}$.

\section{The Proposed Two-Stage Fault Diagnosis Method}

4.1. Architecture of Fault Diagnosis System. This paper presents a two-stage fault diagnosis method; in addition to determining the type of system failure and fault arrays, you can also find which module is broken [8].

The main strategy is to identify the fault array by day and use light scanning method to find the fault module in the fault array by night, and the output is transmitted to the diagnosis system to find the fault module by wireless network transmission. It is able to reduce the time; the maintenance staff finds the fault significantly.

This paper first uses PSIM simulation software to create a $2.2 \mathrm{~kW}$ solar power system, as shown in Figure 6 . The proposed perturb and observe method of maximum power point tracking is used $\mathrm{C} / \mathrm{C}++$ to design and turn maximum power point tracking into dynamically link file (DLL) as the function module of PSIM simulation software. The fault dates of the PV system include fault locations, operation conditions and the output features, and then identify how many fault arrays in fault range, but we cannot know which module is broken. It makes maintenance staff waste time to find the fault module, so we use fault diagnosis by night to enhance the efficiency of repair.

We can know the fault range and how many fault modules by diagnosis system based on output power by day, but we cannot diagnose which module is broken accurately, when we use the fault diagnosis by night. We observe the change of photovoltaic module by light and use Modbus to convert analog signal into digital signal (A/D conversion). With RS-485 transmitting output signal to the ZigBee wireless network transmitter (A), then the receiver (B) accepts the signal, and the last transmission from RS232 turns into USB2.0 to the computer monitor to find location of the fault module. It is able to significantly reduce the maintenance staff to find the fault module. Figure 7 is the architecture of diagnosis system for remote photovoltaic power generation [9].

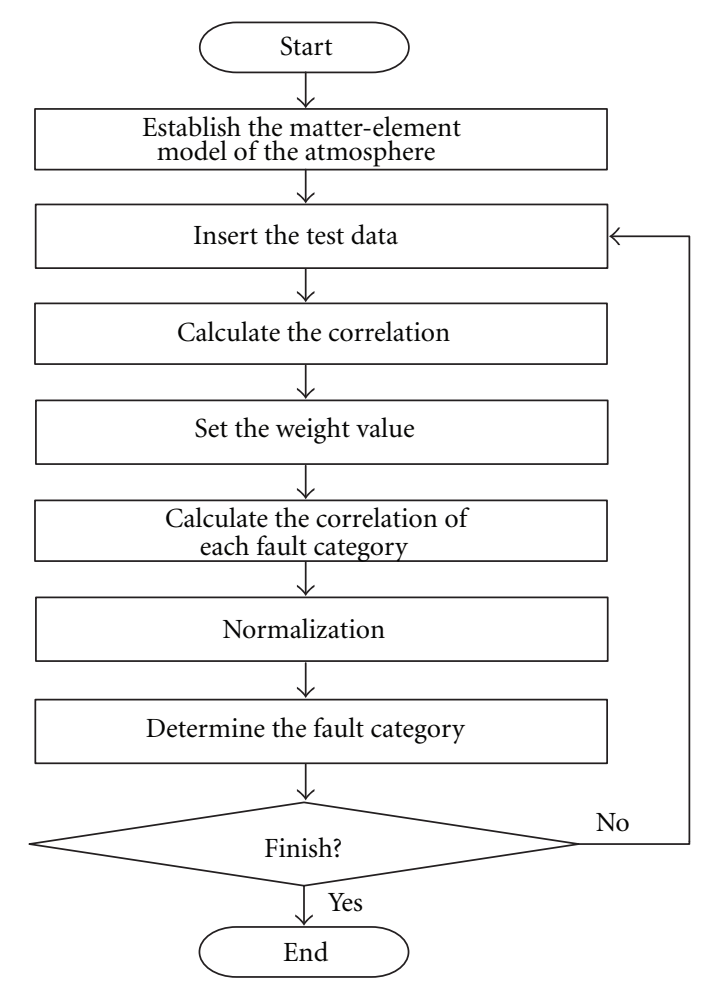

FIGURE 8: The flowchart of the first stage fault diagnosis.

4.2. The Proposed Fault Diagnosis Method. The output voltage, current and power of photovoltaic power generation system have a lot change by sunshine intensity and temperature. When sunshine intensity is low, the characteristic values change a little; it is easy to misjudge. Therefore, the proposed fault diagnosis method set up the operation conditions of PV systems in usually weathers, the sunlight intensity range is $301 \mathrm{~W} / \mathrm{m}^{2}$ to $1000 \mathrm{~W} / \mathrm{m}^{2}$, and the temperature range is $11^{\circ} \mathrm{C}$ to $40^{\circ} \mathrm{C}$, according to sunshine intensity and temperature; the workspace of solar power generation system can be divided into 21 intervals. We can divide 21 intervals according to the different atmospheric condition; the output voltage, current and power of each interval are also different. If we want to know which range is broken, we must create the matter-element model of each failure category in atmosphere. We can divide the fault category into eight categories for the proposed fault diagnosis method of solar power arrays, as shown in Table 2. In addition, when the solar array module fault occurs, it causes the output voltage, current and power to be in recession clearly, and we can determine what kind of solar power array fault occurs according to the recession situation of the output value; at the same time the system is affected by temperature and sunlight intensity, so this paper converts the output voltage, current, power, sunlight intensity, and temperature into the characteristics of the solar power system fault diagnosis to determine whether the system is broken.

We can know the fault range and how many fault modules based on output power and the fault diagnosis system of solar power system by day, but we cannot know 


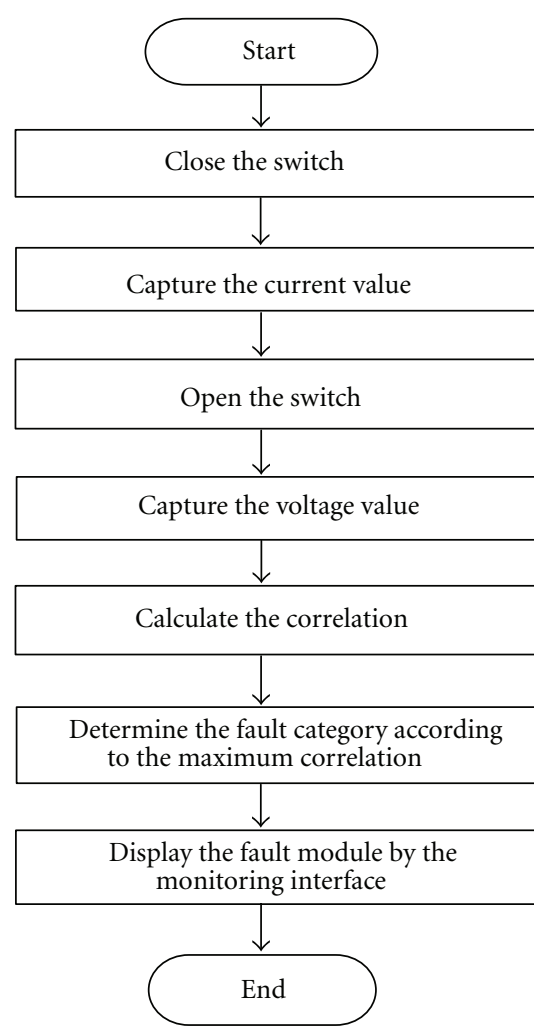

FIGURE 9: The flowchart of the second stage fault diagnosis.

TABLE 2: Fault categories of photovoltaic array.

\begin{tabular}{lc}
\hline $\begin{array}{l}\text { Fault } \\
\text { categories }\end{array}$ & Fault reasons \\
\hline $\mathrm{PF}_{1}$ & Normal \\
$\mathrm{PF}_{2}$ & One module is broken in solar power array \\
$\mathrm{PF}_{3}$ & Two modules are broken in solar power array \\
$\mathrm{PF}_{4}$ & Three modules are broken in solar power array \\
$\mathrm{PF}_{5}$ & Over three modules are broken in solar power array \\
$\mathrm{PF}_{6}$ & $25 \%$ shelter failure occurs in photovoltaic array \\
$\mathrm{PF}_{7}$ & $50 \%$ shelter failure occurs in photovoltaic array \\
$\mathrm{PF}_{8}$ & $75 \%$ shelter failure occurs in photovoltaic array \\
\hline
\end{tabular}

which module is broken, when we use the fault diagnosis by night. we use light scanning to fault arrays by opening and closing the switch and retrieve output voltage $\left(V_{o}\right)$ and output current $\left(I_{o}\right)$ as the characteristic of photovoltaic modules fault diagnosis. The capture output voltage and current are through ZigBee wireless network to the monitor system. In order to know accurately which photovoltaic module is broken and the fault area of the module, we divide the fault category of the module into 17 categories, as shown in Table 3.
TABLE 3: The fault category of the module.

\begin{tabular}{|c|c|}
\hline FN1 & Normal operation \\
\hline $\mathrm{FN}_{2}$ & $\begin{array}{l}\text { The first module occurs } 100 \%-70 \% \text { covered } \\
\text { failure; the other modules are normal }\end{array}$ \\
\hline $\mathrm{FN}_{3}$ & $\begin{array}{l}\text { The second module occurs } 100 \%-70 \% \text { covered } \\
\text { failure; the other modules are normal }\end{array}$ \\
\hline $\mathrm{FN}_{4}$ & $\begin{array}{l}\text { The third module occurs } 100 \%-70 \% \text { covered } \\
\text { failure; the other modules are normal }\end{array}$ \\
\hline $\mathrm{FN}_{5}$ & $\begin{array}{l}\text { The fourth module occurs } 100 \%-70 \% \text { covered } \\
\text { failure; the other modules are normal }\end{array}$ \\
\hline $\mathrm{FN}_{6}$ & $\begin{array}{l}\text { The first module occurs } 70 \%-31 \% \text { covered } \\
\text { failure; the other modules are normal }\end{array}$ \\
\hline $\mathrm{FN}_{7}$ & $\begin{array}{l}\text { The second module occurs } 70 \%-31 \% \text { covered } \\
\text { failure; the other modules are normal }\end{array}$ \\
\hline $\mathrm{FN}_{8}$ & $\begin{array}{l}\text { The third module occurs } 70 \%-31 \% \text { covered } \\
\text { failure; the other modules are normal }\end{array}$ \\
\hline $\mathrm{FN}_{9}$ & $\begin{array}{l}\text { The fourth module occurs } 70 \%-31 \% \text { covered } \\
\text { failure; the other modules are normal }\end{array}$ \\
\hline $\mathrm{FN}_{10}$ & $\begin{array}{l}\text { The first module occurs under } 30 \% \text { covered } \\
\text { failure; the other modules are normal }\end{array}$ \\
\hline $\mathrm{FN}_{11}$ & $\begin{array}{l}\text { The second module occurs under } 30 \% \text { covered } \\
\text { failure; the other modules are normal }\end{array}$ \\
\hline $\mathrm{FN}_{12}$ & $\begin{array}{l}\text { The third module occurs under } 30 \% \text { covered } \\
\text { failure; the other modules are normal }\end{array}$ \\
\hline $\mathrm{FN}_{13}$ & $\begin{array}{l}\text { The fourth module occurs under } 30 \% \text { covered } \\
\text { failure; the other modules are normal }\end{array}$ \\
\hline $\mathrm{FN}_{14}$ & $\begin{array}{l}\text { The first module and second module occur under } \\
\text { covered failure }\end{array}$ \\
\hline $\mathrm{FN}_{15}$ & $\begin{array}{c}\text { The second module and third module occur } \\
\text { under covered failure }\end{array}$ \\
\hline $\mathrm{FN}_{16}$ & $\begin{array}{l}\text { The third module and fourth module occur under } \\
\text { covered failure }\end{array}$ \\
\hline $\mathrm{FN}_{17}$ & $\begin{array}{l}\text { The first module and fourth module occur under } \\
\text { covered failure }\end{array}$ \\
\hline
\end{tabular}

\section{The Proposed Extension Fault Diagnosis Method}

The proposed extension theory is applied to the fault diagnosis of photovoltaic power generation system described as follows. The procedure of the two-stage fault diagnosis is shown in Figures 8 and 9 [10].

Step 1. Create each fault element model in the atmosphere

$$
R_{q}=\left(F, c, v_{k}\right)=\left[\begin{array}{ccc}
F_{0} & v_{\text {out }} & \left\langle a_{k 1 q}, b_{k 1 q}\right\rangle \\
& p_{\text {out }} & \left\langle a_{k 2 q}, b_{k 2 q}\right\rangle \\
& i_{\text {out }} & \left\langle a_{k 3 q}, b_{k 3 q}\right\rangle \\
& t & \left\langle a_{k 4 q}, b_{k 4 q}\right\rangle \\
& s & \left\langle a_{k 5 q}, b_{k 5 q}\right\rangle
\end{array}\right],
$$


Step 2. Insert the test output signal; the matter model is

$$
R_{y}=\left[\begin{array}{ccc}
F_{y} & v_{\text {out }} & v_{y 1} \\
& p_{\text {out }} & v_{y 2} \\
& i_{\text {out }} & v_{y 3} \\
& t & v_{y 4} \\
& s & v_{y 5}
\end{array}\right] .
$$

Step 3. Calculate the correlation function of the test element and the fault matter element:

$$
\begin{gathered}
K_{t j}\left(v_{i j}\right)= \begin{cases}\frac{-\rho\left(v_{i j}, V_{t j}\right)}{\left|V_{t j}\right|}, & \text { if } v_{i j} \in V_{t j}, \\
\frac{\rho\left(v_{i j}, V_{t j}\right)}{\rho\left(v_{i j}, V_{t j}^{\prime}\right)-\rho\left(v_{i j}, V_{t j}\right)}, & \text { if } v_{i j} \notin V_{t j},\end{cases} \\
\rho\left(v_{i j}, V_{t j}\right)=\left|v_{i j}-\frac{a_{t j}+b_{t j}}{2}\right|-\frac{\left(b_{t j}-a_{t j}\right)}{2}, \\
\rho\left(v_{i j}, V_{t j}^{\prime}\right)=\left|v_{i j}-\frac{m_{t j}+n_{t j}}{2}\right|-\frac{\left(n_{t j}-m_{t j}\right)}{2}, \\
i=1,2,3, \ldots, 8, j=1,2,3,4,5 .
\end{gathered}
$$

Step 4. Select the weight values of each characteristic $W 1, W 2, W 3, W 4, W 5$. It represents the importance of each characteristic; the weight values are all 0.2.

Step 5. Calculate the correlation of the fault:

$$
\lambda_{t}=\sum_{j=1}^{5} W_{j} K_{t j}, \quad t=1,2, \ldots, 8 .
$$

Step 6. Normalize values of the relation indexes selected into an interval between -2 and 1 ; this process will produce benefits for fault diagnosis.

Step 7. Determine the fault category of solar power arrays.

Step 8. If there is the next record, it will return to Step 2; otherwise the diagnosis is over.

In order to know the location of the fault module, we use the second stage diagnosis by night; the step is as follows.

Step 1. We command the switch to close through the monitor interface and retrieve the characteristic value of current, then transmitting to monitor interface by ZigBee wireless network.

Step 2. We command the switch to open through the monitor interface and retrieve the characteristic value of voltage, then transmitting to monitor interface by ZigBee wireless network.

Step 3. We can check the data of solar modules by extension fault diagnosis program, including the set of classical domain, joint domain, and weight value. The weight values are setting $W 1=0.15, W 2=0.1, W 3=0.15, W 4=0.1$, $W 5=0.15, W 6=0.1, W 7=0.15, W 8=0.1$.

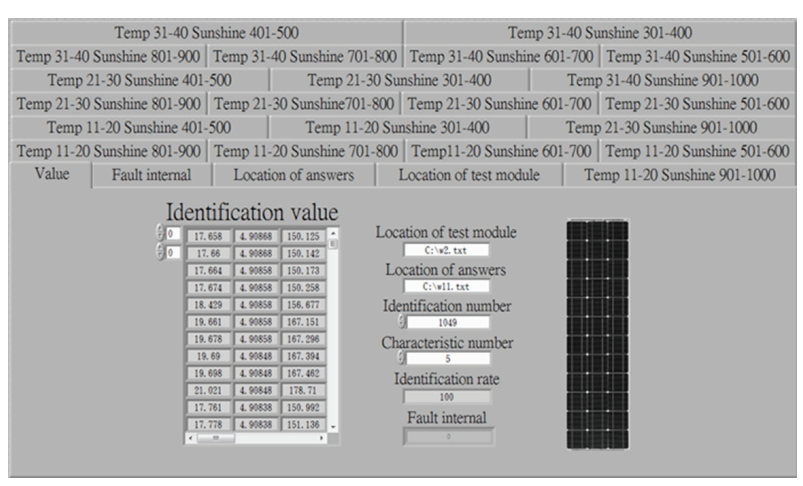

Figure 10: The fault diagnosis system of the solar power system.

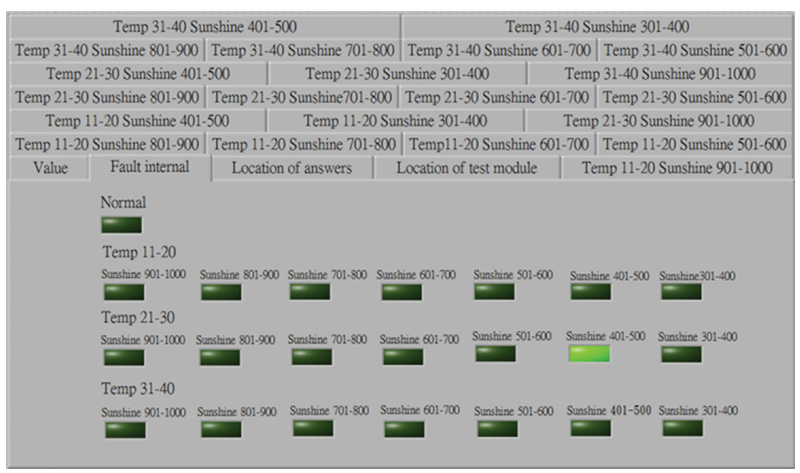

FIgURE 11: The display interface of fault interval.

Step 4. We identify the category according to the correlation maximum and display the result by monitor system.

\section{Experimental Results and Discussion}

To diagnose the fault category accurately, we create the database of fault category in different sunlight intensity and temperature (21 intervals) and show the fault category through the fault diagnosis interface. The diagnosis system is established by LabVIEW to know the system condition, as shown in Figure 10. We can know the fault interval in the system in Figure 10, a typical fault case is shown in Figure 11, where the interface window displays that the 14th interval of the PV system is broken; we identify how many modules are broken from the fault interval, as shown in Figure 12. We can know there are over three modules broken in this fault interval to help us know how many fault modules are broken in the array. Therefore, we can know which interval and how many modules are broken, but we cannot identify which one is broken; to identify which module is broken more accurately, we diagnose by night.

To verify superiority of the proposed fault diagnosis method, we compare multilayer neural network identification method and K-means clustering method in the same data and the comparison result of fault diagnosis by day, as shown in Table 4 . The highest accuracy of multilayer neural network identification method is $92.5 \%$, the accuracy of K-means clustering method is $62.5 \%$, and the accuracy 


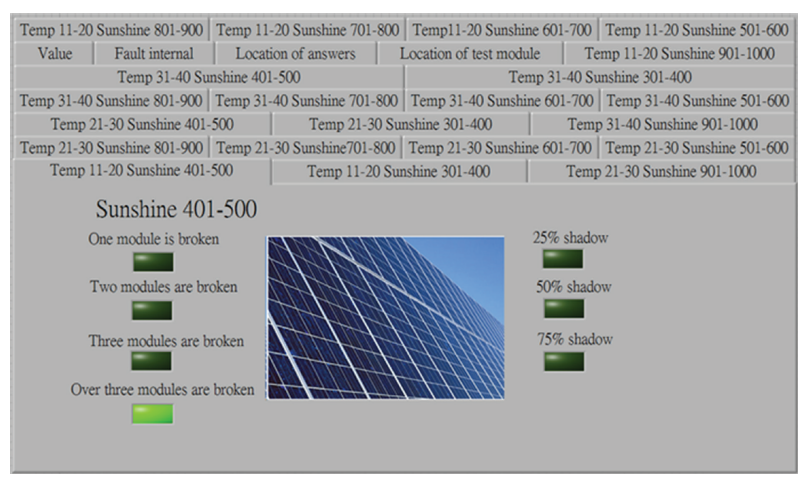

FIGURE 12: The display interface of fault diagnosis.

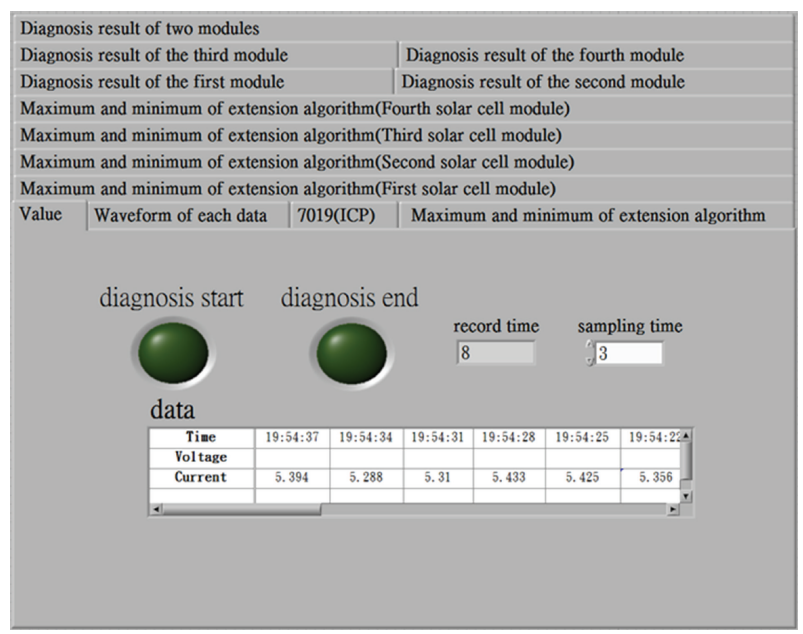

FIGURE 13: Photovoltaic module fault diagnosis system.

of the proposed fault diagnosis method is $100 \%$. From the diagnosis result we can know the proposed fault diagnosis method is better than the other way.

Because the diagnosis by day only finds the fault array and cannot know the location of the fault module, we must perform the diagnosis by night. At first we use the halogen to light the known fault mobile serial module and change the switch and use Modbus to capture the voltage and current signal; then converting signal to the fault diagnosis system of photovoltaic modules, the diagnosis system is created by LabVIEW, as shown in Figure 13. The diagnosis result is shown in Figure 14, and we can know what happens in the module. In addition, the database of each signal is established by the system to help staff analyze and inquire in the future. Figures 15 and 16 are voltage and current waveform that the first module is broken; the fault diagnosis system transmits a signal every three seconds.

Table 5 is the comparison of the fault diagnosis result by night; the accuracy of multilayer neural network identification method and K-means clustering method is lower than the proposed method in this paper, so we can understand the superiority of using extension theory in the fault diagnosis. Consider the noise and interference of the wireless

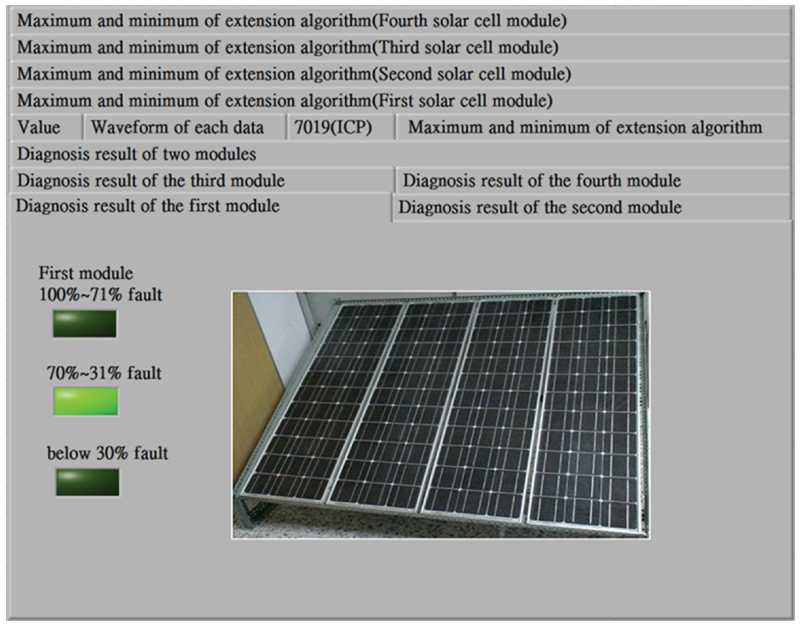

FIgURE 14: The interface of diagnosis result.

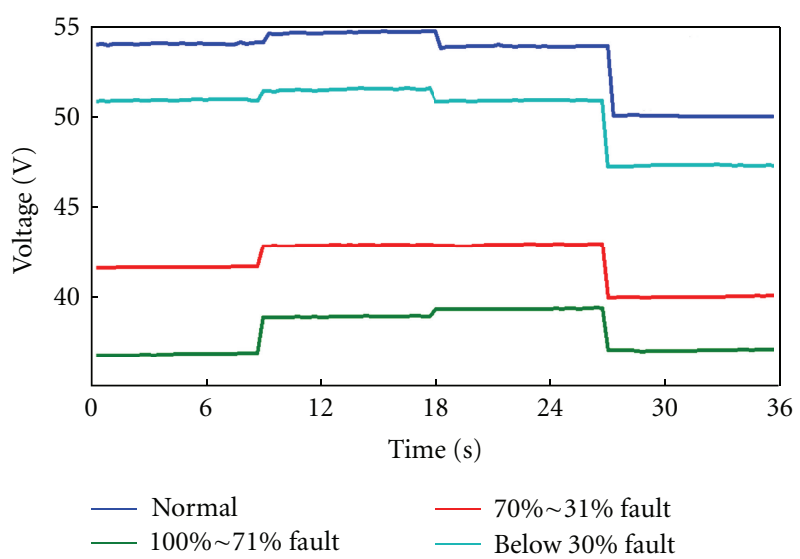

FIGURE 15: Each fault voltage curve in the first module.

transmission, so we randomly add the geometric error of $\pm 5 \%$ to $\pm 20 \%$ to compare the fault tolerance of the proposed method in this paper, as shown in Table 6. Even if the data error reaches $\pm 20 \%$, it still has $60 \%$ accuracy, so the proposed method in this paper is very useful.

\section{Conclusion}

We establish a $2.2 \mathrm{~kW}$ solar power system by PSIM software in this paper and simulate the condition of normal operating and fault category under atmospheric condition. There are eight categories and five characteristics in each atmosphere range through the fault diagnosis by day; we can identify the fault module accurately. Then using the output voltage and current of each photovoltaic module to be the characteristic, we diagnose the fault array by night in eight characteristics and seventeen different operation conditions to determine the location of the fault module accurately. We provide a few conclusions from this paper. 
TABLE 4: The results of the fault diagnosis by day in different ways.

\begin{tabular}{lccc}
\hline Test method & Learning times & Learning accuracy (\%) & Test accuracy $(\%)$ \\
\hline The proposed method & no & no & $100 \%$ \\
K-means clustering method & no & $69.17 \%$ & $62.5 \%$ \\
Multilayer neural network I (5-8-8) & 1000 & $85.83 \%$ & $83.33 \%$ \\
Multilayer neural network II (5-10-8) & 1000 & $87.5 \%$ & $86.67 \%$ \\
Multilayer neural network III (5-12-8) & 1000 & $93.33 \%$ & $92.5 \%$ \\
\hline
\end{tabular}

TABLE 5: The results of the fault diagnosis by night in different ways.

\begin{tabular}{lccc}
\hline Test method & Learning times & Learning accuracy (\%) & Test accuracy $(\%)$ \\
\hline The proposed method & no & no & $98.04 \%$ \\
K-means clustering method & no & $63.73 \%$ & $57.84 \%$ \\
Multilayer neural network I (5-8-8) & 1000 & $70.59 \%$ & $66.67 \%$ \\
Multilayer neural network II (5-10-8) & 1000 & $74.51 \%$ & $72.55 \%$ \\
Multilayer neural network III (5-12-8) & 1000 & $82.35 \%$ & $81.37 \%$ \\
\hline
\end{tabular}

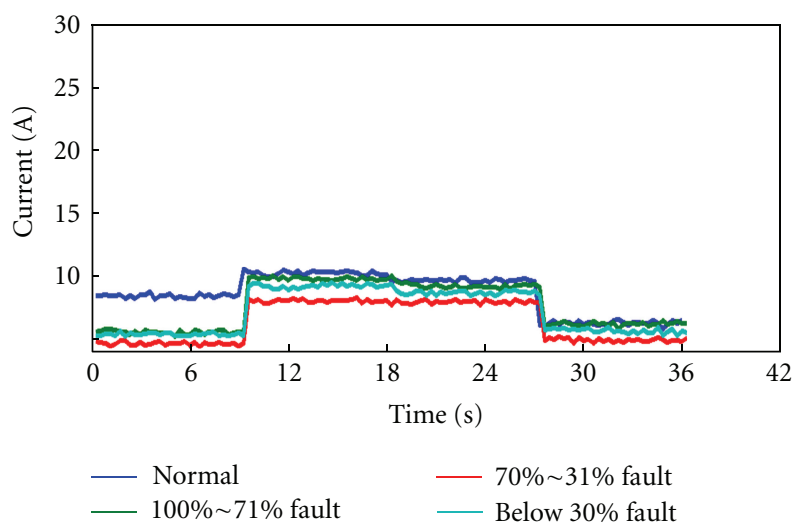

FIGURE 16: Each fault current curve in the first module.

(1) This paper proposes the two-stage fault diagnosis method by extension method. In addition to determining the fault category and the fault array of the photovoltaic power generation system, we can find which module is broken. It dramatically reduces the test time to find the fault module and improves the efficiency of maintenance.

(2) We classify the characteristic parameters of some common fault categories in the photovoltaic solar generation system. The proposed diagnosis method in this paper compares to K-means clustering method and multilayer neural network identification method; from the result we can know the accuracy of the proposed fault diagnosis method in this paper is better than other ways.

(3) The fault diagnosis system can implement remote monitoring with ZigBee wireless network. The proposed method of this paper can be applied in largescale solar power generation plant in the future.
TABLE 6: The test result of the fault tolerance.

\begin{tabular}{lc}
\hline The adding ratio of error & $\begin{array}{c}\text { The recognition of the proposed } \\
\text { fault diagnosis method in this paper }\end{array}$ \\
\hline $\pm 0 \%$ & $98.04 \%$ \\
$\pm 5 \%$ & $95.09 \%$ \\
$\pm 10 \%$ & $86.27 \%$ \\
$\pm 15 \%$ & $78.43 \%$ \\
$\pm 20 \%$ & $61.76 \%$ \\
\hline
\end{tabular}

\section{Acknowledgment}

The authors would like to thank the National Science Council for financial supporting under project no. NSC 99-2221-E167-031-MY2.

\section{References}

[1] Energy Ministry of Economic Affairs Bureau, Energy and Industrial Technology Paper, 2010.

[2] S. Z. Q. Zeng, Solar Photovoltaic Technology, The Five Southern Book Publishing, 2008.

[3] G. Pekhteryev, Z. Sahinoglu, P. Orlik, and G. Bhatti, "Image Transmission over IEEE 802.15.4 and ZigBee networks," in Proceedings of the IEEE International Symposium on Circuits and Systems (ISCAS '05), pp. 3539-3542, Kobe, Japan, May 2005.

[4] W. Cai, "Extension set and incompatible problems," Science Exploration, vol. 3, no. 1, pp. 83-97, 1983.

[5] M. H. Wang, "Application of extension theory to vibration fault diagnosis of generator sets," IEE Proceedings Generation Transmission and Distribution, vol. 151, no. 4, pp. 503-508, 2004.

[6] M. H. Wang, J. C. Yang, and X. H. Li, "Application of extension method to selecting of solar power systems," in Proceedings of the International Symposium on Computer, Communication, Control and Automation (3CA '10), pp. 160-163, Tainan, Taiwan, May 2010. 
[7] M. H. Wang, Y. F. Tseng, H. C. Chen, and K. H. Chao, "A novel clustering algorithm based on the extension theory and genetic algorithm," Expert Systems with Applications, vol. 36, no. 4, pp. 8269-8276, 2009.

[8] M. H. Wang and Y. K. Chung, "A novel extension decisionmaking method for selecting of solar power systems," Renewable \& Sustainable Energy Reviews. In press.

[9] K. H. Chao, P. Y. Chen, M. H. Wang, C. T. Chen, and J. P. Chen, "A fault diagnosis meter based on a ZigBee wireless sensor network for photovoltaic power generation systems," Sensor Letters. In press.

[10] K. H. Chao, S. H. Ho, and M. H. Wang, "Modeling and fault diagnosis of a photovoltaic system," Electric Power Systems Research, vol. 78, no. 1, pp. 97-105, 2008. 


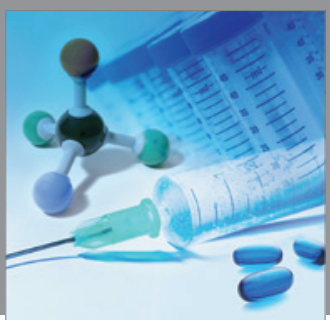

International Journal of

Medicinal Chemistry

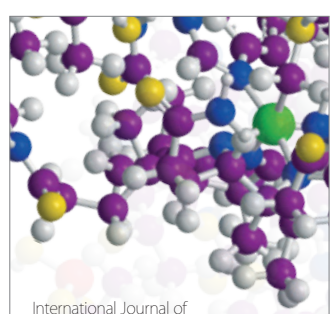

Carbohydrate Chemistry

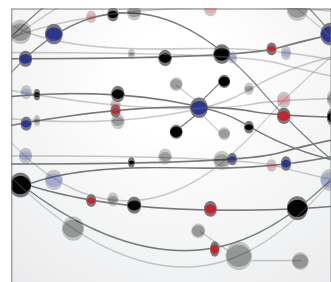

The Scientific World Journal
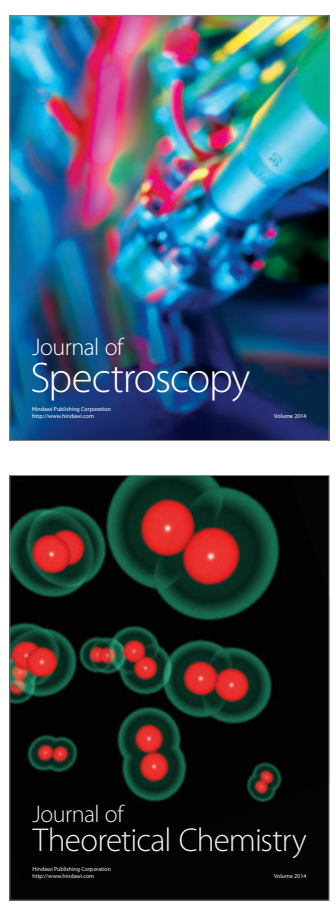
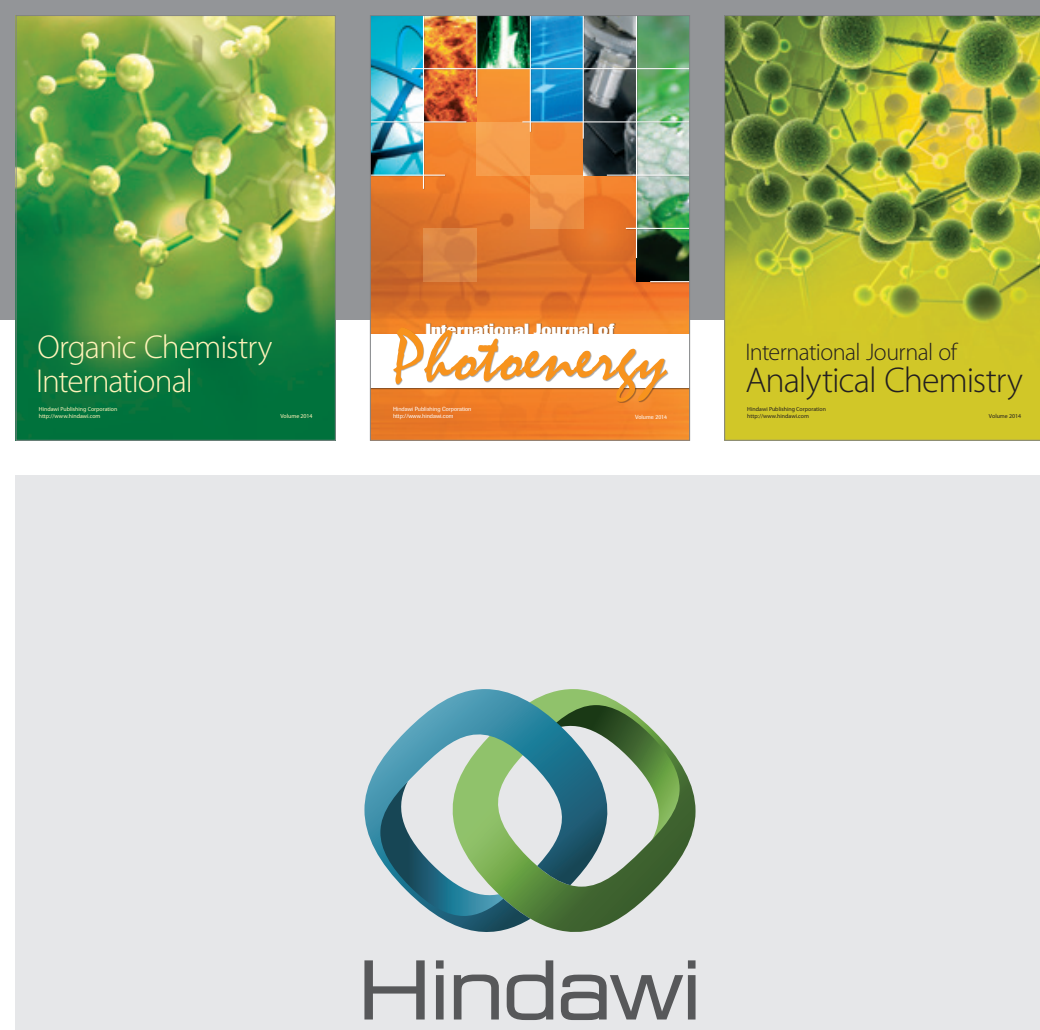

Submit your manuscripts at

http://www.hindawi.com
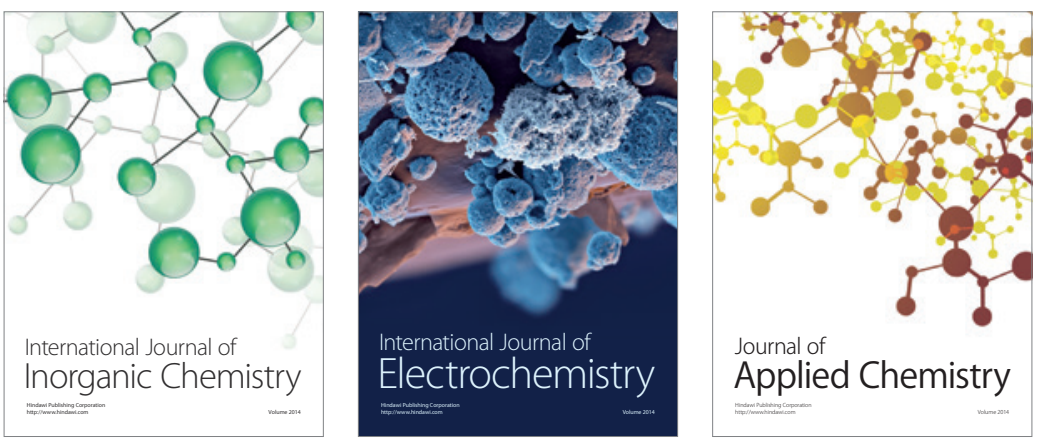

Journal of

Applied Chemistry
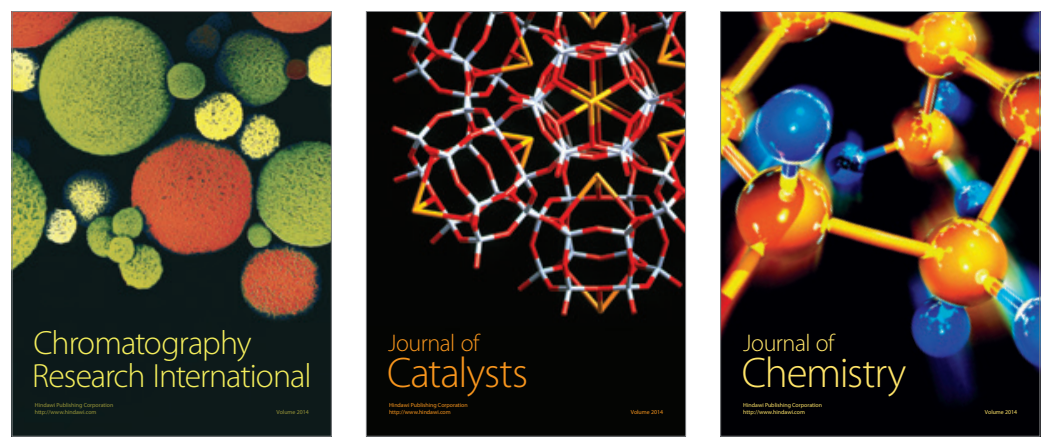
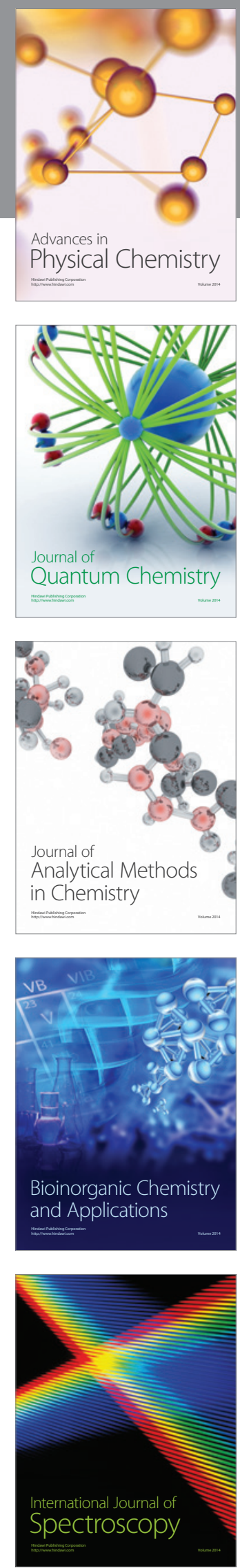